\title{
A laboratory scale synthesis of geopolymer from demolished-cement-sand-mixture
}

\author{
Dipak Paudel, Arvind Pathak and *Vinay Kumar Jha \\ Central Department of Chemistry, Tribhuvan University, Kirtipur, Kathmandu, Nepal \\ (*Email:vinayj2@yahoo.com)
}

\begin{abstract}
The demolition of old houses and the construction of new buildings in Kathmandu valley are in the peak in recent days which in turn generates a huge amount of demolished-cement-sand-mixture (DCSM) waste. This DCSM waste is rich source of alumino-silicate and thus used as raw material for the synthesis of geopolymer in this study. Geopolymers have been synthesized from DCSM waste using $\mathrm{NaOH}$ and $\mathrm{Na}_{2} \mathrm{SiO}_{3}$ as activators. Some parameters like alkali concentration, particle size variation, ratio of $\mathrm{Na}_{2} \mathrm{SiO}_{3}$ to $\mathrm{DCSM}$ waste and curing time have been varied in order to improve the quality of geopolymeric product. The results obtained revealed the maximum compressive strength of $46.95 \mathrm{MPa}$ at the ratio of sodium silicate to DCSM waste of $1.5(\mathrm{w} / \mathrm{w})$ on 28 days curing time at $40{ }^{\circ} \mathrm{C}$ temperature.
\end{abstract}

Keywords: Geopolymer, synthesis, alumino-silicate, waste

Received: 18 March, 2012

Revision accepted: 30 May, 2012

\section{INTRODUCTION}

According to the United Nation Statistics Division (UNSD) "wastes are materials that are not prime products (i.e. product produced in the market) for which the generator has no further use in terms of his/her own purposes of production, transformation or consumption and of which he/ she wants to dispose". Waste may be generated during the extraction and processing of raw materials into intermediate and final products, the consumption of final products and other human activities (United Nations 1997).

In recent years, demolition of old buildings and construction of new ones in most of the major cities is in peak. But due to rapid urbanization and increasing population the empty land spaces are decreasing while land prices are increasing. Several million tons of concrete waste are produced every year due to frequent building demolition and have resulted in drastic reduction in available landfill space due to industrialization and urbanization.

The major composition of the demolished-cement-sandmixture waste is sand and cement which are the major sources of $\mathrm{Al}_{2} \mathrm{O}_{3}$ and $\mathrm{SiO}_{2}$. The prominent application of the aluminosilicate rich materials are the synthesis of light weight aggregates, decontamination of feed contaminated by fungi and mycotoxins, synthesis of zeolites and geopolymer etc.

The term "geopolymer" was coined by Davidovits in 1972 to the tri-dimensional alumino-silicate that are formed at the low temperature and short time by naturally occurring alumino-silicate (Davidovits 1988a). Geopolymer describes a family of mineral binders that have polymeric Si-O-Al framework structure similar to that found in zeolites because they have approximately same $\mathrm{Al}$ : Si ratio.

Geopolymer cement is synthesized from raw material containing alumino-silicate at low temperature which leads to significant reduction in energy consumption and $\mathrm{CO}_{2}$ emission. It is reported by Davidovits that about $3 / 5$ less energy is required and $80-90 \%$ less $\mathrm{CO}_{2}$ is generated for the production of geopolymer cement than that of ordinary Portland cement (OPC) (Davidovits 1994). Thus geopolymer cement reduces global warming and saves energy. Furthermore, geopolymer cement possesses high temperature resistance up to $1200{ }^{\circ} \mathrm{C}$ without properties degradation. This merit of geopolymer can be applied in automotive and aerospace industries. At present, some geopolymeric products have been used in aircraft to eliminate cabin fire and other aircraft accidents (Comrie 1988).

The primary work on geopolymerization was done on kaolinite and metakaolinite by Davidovits. The mixture of granulated blast furnace slag, kaolinite and metakaolinite showed the highest compressive strength of $79 \mathrm{MPa}$ at 28 days and $60{ }^{\circ} \mathrm{C}$ curing time and temperature (Davidovits 1984; Cheng and Chiu 2003). Geopolymer synthesized from metakaolinite at $65^{\circ} \mathrm{C}$ curing temperature for 35 days curing time had the compressive strength of $35 \mathrm{MPa}$ (Wang et al. 2005). The adhesive strength of maetakaolinite based geopolymer coating on stainless and mild steel substrate with the composition of $\mathrm{Si}: \mathrm{Al}=2.5$ were found to have the strength $>3.5 \mathrm{MPa}$ when cured at $70{ }^{\circ} \mathrm{C}$ (Temuujin et al. 2009). The coal combustion fly ashes based geopolymers had gained the compressive strength about $60 \mathrm{MPa}$ when 
treated with $12 \mathrm{M} \mathrm{NaOH}$ and cured at $80{ }^{\circ} \mathrm{C}$ for 48 hours (Álvarez-Ayuso et al. 2008). High strength geopolymers with compressive strength over $100 \mathrm{MPa}$ were obtained from coal fly ash, blast furnace slag with potassium silicate solution and water, in which the fly ash was the major the component (Nugteren et al. 2009). The geopolymers with compressive strength in the range of $12.5-56 \mathrm{MPa}$ were synthesized from fly ash (FA) and rice husk ash (RHA) in which sodium silicate to $\mathrm{NaOH}$ mass ratio was 4 and curing temperature and time were $60{ }^{\circ} \mathrm{C}$ for 48 hours respectively (Detphan and Chindaprasirt 2009). The geopolymers from mechanochemically treated clinoptilolite using $\mathrm{NaOH}$ and sodium silicate solutions showed increasing compressive strength up to around $25 \mathrm{MPa}$ with increasing curing time (Jha and Hayashi 2009).

The demolished-cement-sand-mixture waste is the growing problem in many countries and the present study is the preliminary investigation on the possibility of utilizing construction waste as raw materials in the production of geopolymer cement in order to find out the amicable solution for such problem.

\section{EXPERIMENTAL METHODS}

\section{Sample preparation}

The demolished-cement-sand-mixture (DCSM) waste was selected from demolition area near Nayabazar Kirtipur, Kathmandu and did not include brick and gravel. At first, the pieces of DCSM was ground in iron mortar using pestle with constant sieving until the grain size was reduced to $<100 \mu \mathrm{m}$. The powder was dried on oven at $60^{\circ} \mathrm{C}$.

\section{Preparation of DCSM base geopolymer}

To synthesize geopolymer from cement-concrete waste, several parameters like alkali concentration, powder particle size, amount of sodium silicate and curing time were varied

\section{Variation of $\mathrm{NaOH}$ concentration}

From 2 to $8 \mathrm{~N} \mathrm{NaOH}$ solutions were prepared separately. About 11 gm of DCSM Waste was weighted and was blended manually for 2 minutes with about $4 \mathrm{ml}$ of $\mathrm{NaOH}$ solution of various concentration separately using mortar and pestle. This mixture was then transferred to plastic mould (length $\times$ breadth $\times$ height: $2 \mathrm{~cm} \times 2 \mathrm{~cm} \times 2 \mathrm{~cm}$ ) and was sealed to prevent water loss. Care was taken to avoid air bubbles. This mould was placed in oven for curing at $40^{\circ} \mathrm{C}$ for 6 days

\section{Variation of particle size}

The DCSM was grounded and sieved in various size sieves. The DCSM powder of different sizes such as $\leq 53$, $\leq 75, \leq 90, \leq 120, \mu \mathrm{m}$ was collected. $12 \mathrm{~g}$ of different size powder were weighted separately and mixed with $4 \mathrm{ml}$ of $6 \mathrm{~N} \mathrm{NaOH}$ solution and then transferred into separate plastic mould. Then samples were cured for 10 days at $40^{\circ} \mathrm{C}$.

\section{Variation of sodium silicate concentration}

The variation of mass ratio of sodium silicate to 53 $\mu \mathrm{m}$ sized DCSM powder were set to $0.5,1.0,1.5,2.0$. The mixture was thoroughly mixed with $6 \mathrm{~N} \mathrm{NaOH}(3-3.5 \mathrm{ml})$ for 2 minutes and transferred to plastic moutld. Then moulds were cured for 21 days at $40^{\circ} \mathrm{C}$.

\section{Variation of curing time}

With 1.5 mass ratio of $\mathrm{Na}_{2} \mathrm{SiO}_{3}$ to DCSM powder (53 $\mu \mathrm{m}$ size), the mixture was mixed in the mortar using $6 \mathrm{~N}$ $\mathrm{NaOH}(3.5 \mathrm{ml})$ manually. The mixture was then transferred to plastic mould and cured for 7-28 days in oven at $40{ }^{\circ} \mathrm{C}$. After curing, the solid sample was removed from plastic mould and polished in various sized sand papers (from 400800 sizes) to get its smooth surface. The area of the solid smooth sample was measured using vernier calliper and was weighed.

The compressive strength of the prepared geopolymers was measured using SLF Load from machine at central material Testing Laboratory, Institute of Engineering Pulchowk Campus, Tribhuvan University. Each data of the compressive strength presented in this paper is the average of three consecutive measurements. The raw samples and fragment from the crushing tests of few characteristic samples were powdered and examined by X-ray diffraction (Bruker D8 Advance Diffractometer, Germany) available at Central Department of Geology, Tribhuvan University, Kirtipur, Kathmandu.

\section{RESULTS AND DISCUSSION}

\section{Characterization of waste powder}

The raw DCSM was grounded and sieved. The different sizes portions of the powder were separated. The XRD patterns of DCSM of various particle sizes $(\leq 53-\leq 120 \mu \mathrm{m})$ were obtained and are shown in Fig. 1.

The XRD patterns of the DCSM raw materials of various sizes in Fig. 1 have shown the presence of mainly muscovite, 


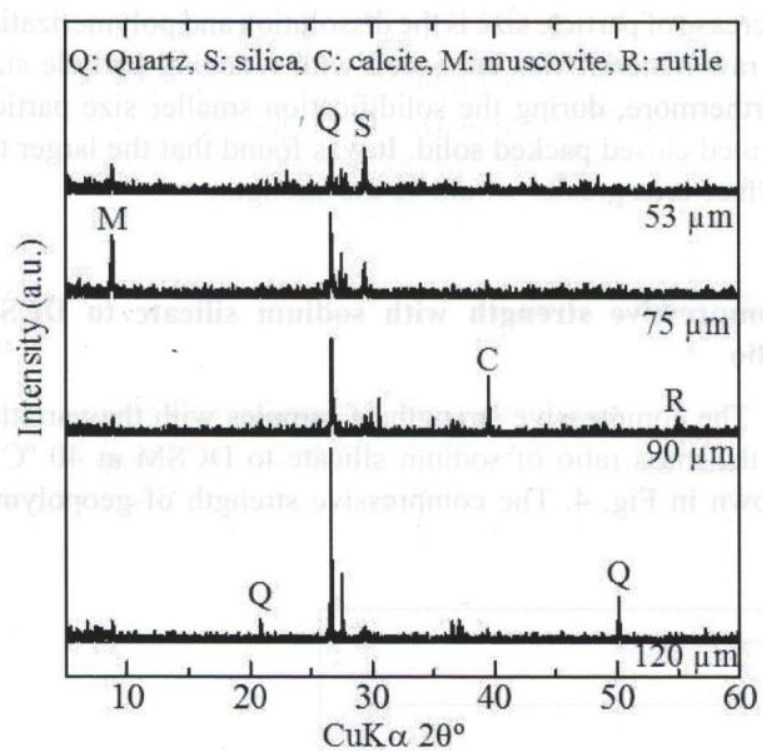

Fig. 1: XRD patterns of raw DCSM of different particle size $(53-120 \mu \mathrm{m})$.

quartz, rutile, calcite and silica. The quartz peak $\left(2 \theta=26.69^{\circ}\right)$ was diminished with decreasing the size of particle. Several another peaks were diminished with decreasing particle size while a new peak at $2 \theta=27.68^{\circ}$ was appeared which was characterized as $\mathrm{SiO}_{2}$. This was expected to be due to the conversion of quartz to silica during the process of mechanical grinding.

It has been reported that mechanical milling can enhance the transformation of crystalline to amorphous phase (El-
Eskandarany et al. 1997). The diminishing of several XRD peaks and increase of the amorphous nature of the sample with reducing particle size attributed to the fact that the mechanical grinding increases the collision frequency which in turn leads to faster diffusion process (Lü and Lai 1998).

\section{Compressive strength with $\mathrm{NaOH}$ concentration variation}

Fig. 2 represents the compressive strength of samples with the variation of $\mathrm{NaOH}$ concentration. The compressive strength initially increased and then decreased showing the maximum strength of $2.943 \mathrm{MPa}$ at $6 \mathrm{~N} \mathrm{NaOH}$.

The above results can be interpreted as follows. The dissolution of alumino-silicate take place under alkaline solution and the higher amount of hydroxyl ion facilitate the dissolution of different silicate and aluminate species promoting polymerization (Davidovits 1988b; Yip et al. 2005). But under high alkaline condition the connectivity of silicon anion may be reduced which causes aluminasilicate gel to precipitate at early stage resulting in poor polymerization i.e. $\mathrm{NaOH}$ molecule is incorporated between two geopolymer precursors which break the silicon anion connectivity thus preventing polymerisation (Singh et al. 2005).

Further, the excess $\mathrm{NaOH}$ forms $\mathrm{Na}_{2} \mathrm{CO}_{3}$ by atmospheric carbon (Barbosa et al. 1999). Due to these reasons, the excess concentration of $\mathrm{NaOH}$ causes the decrease in compressive strength. Having small size, $\mathrm{Na}^{+}$can form strong pair with

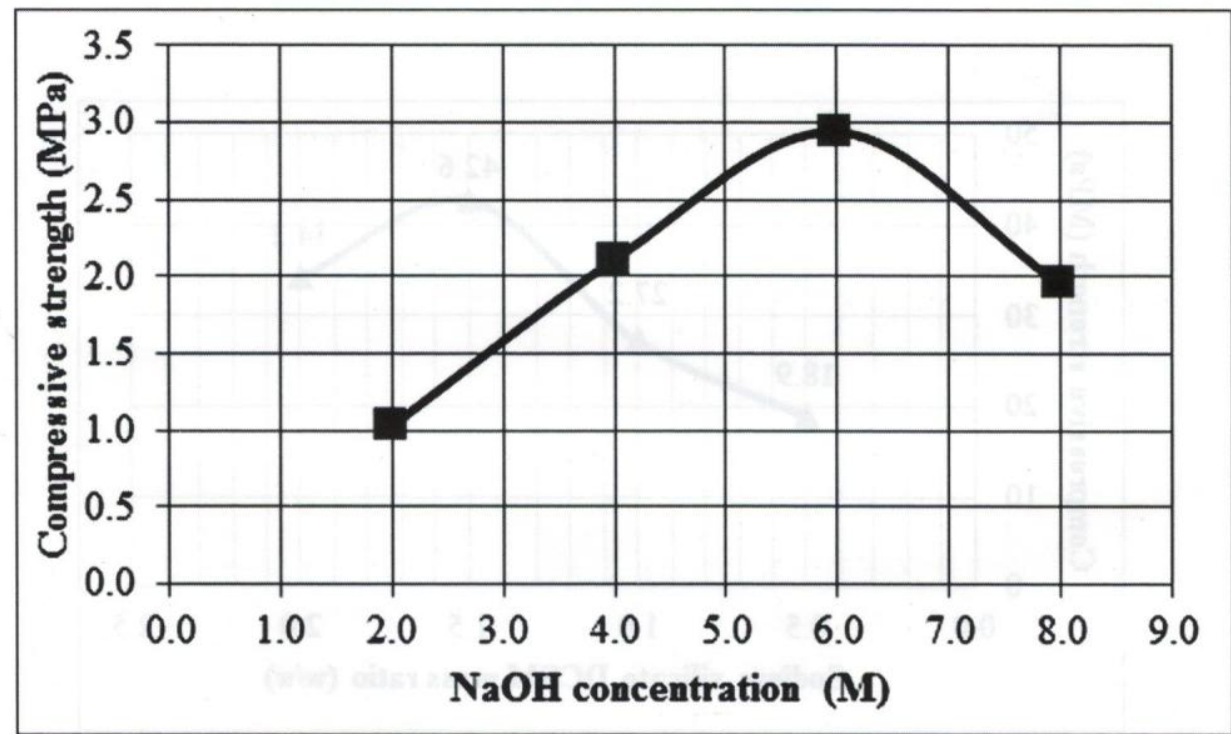

Fig. 2: Plot of compressive strength as a function of $\mathrm{NaOH}$ concentration where curing time and temperature were kept constant. 
small silicate oligomers and thus stabilize silicate monomer and dimmer; enhancing mineral dissolution (Komnitsas and Zaharaki 2007).

\section{Compressive strength with particle size variation}

Fig. 3 represents the compressive strength of geopolymeric products with variation of size of DCSM. Here the compressive strength was found decreasing with increase of particle size.

The reason behind the increase of compressive strength with decrease of particle size is the dissolution and polymerization of raw material was enhanced with reducing particle size. Furthermore, during the solidification smaller size particle formed closed packed solid. It was found that the larger the surface area greater would be the strength.

\section{Compressive strength with sodium silicate to DCSM ratio}

The compressive strength of samples with the variation of the mass ratio of sodium silicate to DCSM at $40{ }^{\circ} \mathrm{C}$ is shown in Fig. 4. The compressive strength of geopolymer

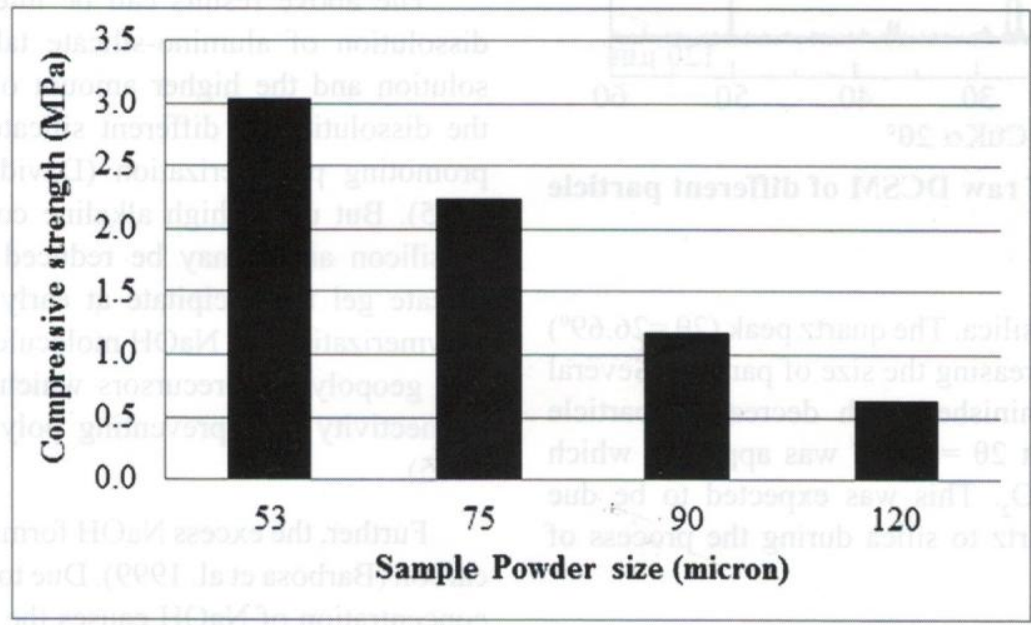

Fig. 3: Plot of compressive strength as a function of particle size variation of DCSM where NaOH concentration, curing time and temperature were kept constant.

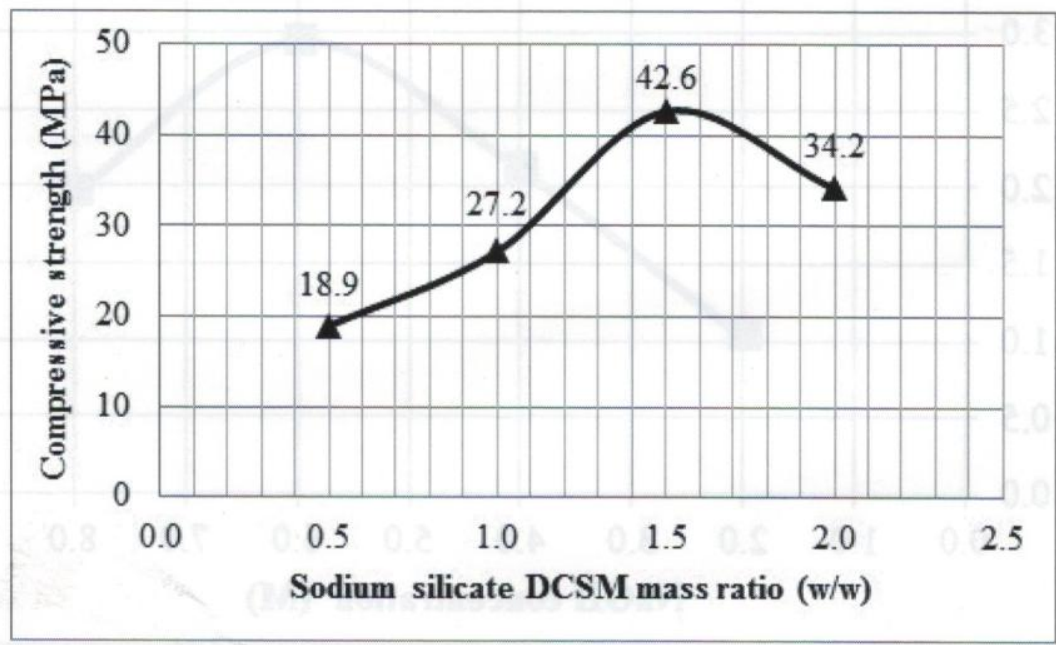

Fig. 4: Plot of compressive strength as a function of mass ratio of $\mathrm{Na}_{2} \mathrm{SiO}_{3}$ to $\mathrm{DCSM}$ where particle size, $\mathrm{NaOH}$ concentration, curing time and temperature were kept constant. 
was first found to increase and decreased with maximum compressive strength of $42.63 \mathrm{MPa}$.

It can be well observed from Fig. 2 that after the addition of $\mathrm{Na}_{2} \mathrm{SiO}_{3}$ the compressive strength increases. This is because at higher concentration of silicates, the stronger ion pair formation is expected which results in formation of longer chain silicate oligomer as well as $\mathrm{Al}-\mathrm{O}-\mathrm{Si}$ complexes (McCormick et al. 1989). Thus added silica acts as a binder shown in the reaction below. But the increased silica decreases the rate of geopolymerization (Provis and van Deventer 2007a) and also in high silica system; solidification of the paste prior to reaction completion may occur (Provis and van Deventer 2007b). This may be the probable reason why increase in amount of silicate causesdecreases in compressive strength.

Further, it is believed that the amount of unreacted materials in the specimen with higher silica content act as the defect site and has the negative effect on strength (Davidovits 1984).

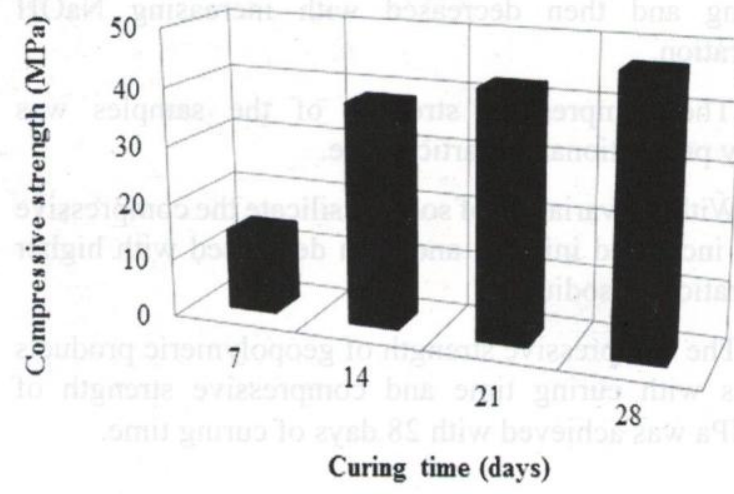

Fig. 5: Change in compressive strength with the variation of curing time where particle size, $\mathrm{NaOH}$ concentration, sodium silicate to DCSM mass ratio and curing temperature were kept constant.

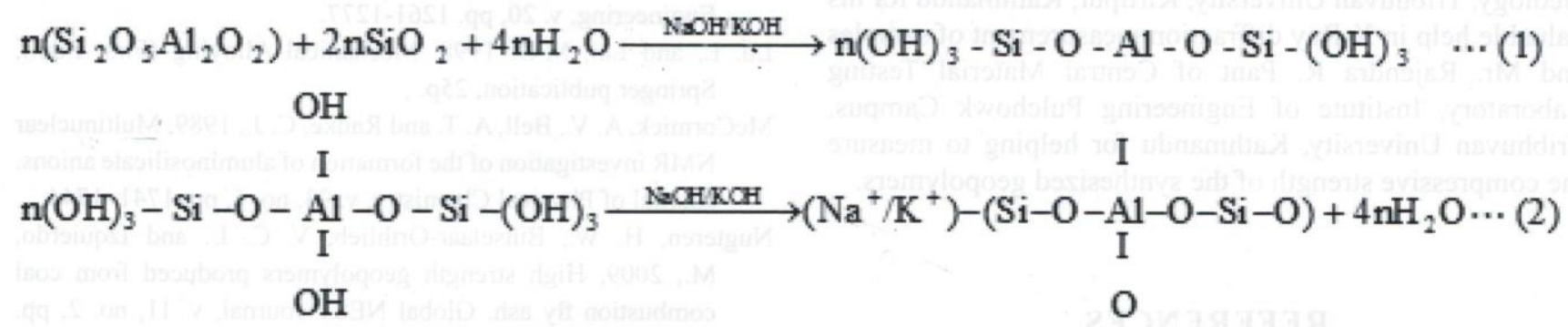

In the above formula (1) $\left(\mathrm{SiO}_{5} \mathrm{Al}_{2} \mathrm{O}_{2}\right)$ is an emphasized form to stand out the IV fold co-ordination of $\mathrm{Al}$ instead of conventional alumino-silicate oxides form of $\left(2 \mathrm{SiO}_{2}\right.$. $\left.\mathrm{Al}_{2} \mathrm{O}_{3}\right) \cdot \mathrm{SiO}_{2}$ in formula (1) is a monomer or polymer form which comes from silicate added later. Formula (2) shows the final backbone of the geopolymer and charge balance in the matrix.

\section{Compressive strength with curing time variation}

The compressive strength of geopolymeric products with the variation of curing time at $40{ }^{\circ} \mathrm{C}$ is shown in Fig. 5. The compressive strength increases with increase in the curing time with the maximum compressive strength of $46.95 \mathrm{MPa}$. The strength continues to rise further as shown in the graph above.

Unlike cement, which has fixed life span about 50 years and after which compressive strength decreases, the strength of geopolymer tends to rise. Egyptian pyramid can be taken as the example. This is because once the stable 3D structure of geopolymer is formed it can stay intact for centuries until and unless crack develop due to several reasons like earthquake and also the resistivity against fire, chemical and high temperature $\left(1200{ }^{\circ} \mathrm{C}\right)$ add the quality of geopolymer but these parameters deteriorates the cement rapidly.

The curing for longer period of time at low temperature is preferable for the synthesis of geopolymer as at low temperature condensation of geopolymer precursors and evaporation of the water molecules takes place simultaneously preventing the formation of voids and cracks inside the material thus increasing the compressive strength.

\section{CONCLUSIONS}

The geopolymer was synthesized by using various concentration of alkali activator i.e. $\mathrm{NaOH}$ and $\mathrm{Na}_{2} \mathrm{SiO}_{3}$. The parameter like size variation, amount of sodium silicate and curing time were studied at $40{ }^{\circ} \mathrm{C}$ curing temperature. The following conclusions were drawn from the experimental results of the study:

(i) The compressive strength was found initially 
increasing and then decreased with increasing $\mathrm{NaOH}$ concentration.

(ii) The compressive strength of the samples was inversely proportional to particle size.

(iii) With the variation of sodium silicate the compressive strength increased initially and then decreased with higher concentration of sodium.

(iv) The compressive strength of geopolymeric products increases with curing time and compressive strength of $46.95 \mathrm{MPa}$ was achieved with 28 days of curing time.

\section{ACKNOWLEDGEMENTS}

The authors are thankful to Nepal Academy of Science and Technology for offering the project on geopolymer synthesis. We would like to acknowledge Assoc. Prof. Dr. Lalu Prasad Paudel, Head of Central Department of Geology, Tribhuvan University, Kirtipur, Kathmandu for his valuable help in X-Ray diffraction measurement of samples and Mr. Rajendra R. Pant of Central Material Testing Laboratory, Institute of Engineering Pulchowk Campus, Tribhuvan University, Kathmandu for helping to measure the compressive strength of the synthesized geopolymers.

\section{REFERENCES}

Álvarez-Ayuso, E. A., Querol, X., Plana, F., Alastuey, A., Moreno, N., MIzquierdo, M., Font, O., Moreno, T., Diez, S., Vázquez, E. and Barra, M., 2008, Environmental, physical and structural characterisation of geopolymer matrixes synthesised from coal (co-)combustion fly ashes, Journal of Hazardous Materials, v. 154, pp. 175-183.

Barbosa, V. F. F., MacKenzie, K. J. D. and Thaumaturgo, C., 1999, Synthesis and characterization of sodium polysialate inorganic polymer based on alumina and silica. Proceedings of the $2^{\text {nd }}$ International Conference on Geopolymer'99, Saint Qunentin, France, 65p.

Cheng, T. W. and Chiu, J. P., 2003, Fire-resistant geopolymer produced by granulated blast furnace slag, Minerals Engineering, v. 16, pp. 205-210.

Comrie, 1988, Preliminary examination of the potential of geopolymers for use in mine tailings management. D. Comrie Consulting Ltd., Mississauga, Ontario, Canada.

Davidovits, J., 1984, Synthetic mineral polymer compound of the silicoaluminates family and preparation process. US Patent: $4,472,199$.

Davidovits, J., 1988a, Long term durability of hazardous toxic and nuclear waste disposals. Proceedings of the 1st International Conference on Geopolymer'88, Compiegne, France, v. 1, pp. $125-134$.
Davidovits, J., 1988b, Soft Mineralurgy and Geopolymers. Proceedings of the 1st International Conference on Geopolymer '88, Compiegne, France, v. 1, pp. 19-23.

Davidovits, J., 1994, Properties of Geopolymer Cements. 1st International Conference on Alkaline Cements and Concretes Kiev, Ukraine, (SRIBM, Kiev State Technical University), pp. 131-149.

Detphan, S. and Chindaprasirt, P., 2009, Preparation of fly ash and rice husk ash geopolymer. International Journal of Minerals, Metallurgy and Materials, v. 16, no. 6, pp. 720-726.

El-Eskandarany, M. S., Sumiyama, K. and Suzuki, K., 1997. Crystalline-to-amorphous phase transformation in mechanically alloyed $\mathrm{Fe}_{50} \mathrm{~W}_{50}$ powders. Acta Materialia, v. 45 , pp. $1175-1187$.

Jha, V. K. and Hayashi, S., 2009, Utilization of Akita's clinoptilolite zeolite for the production of cation exchangers and geopolymers. Science and Technical Reports of Faculty of Engineering and Resource Science, Akita University, v. 30, pp. $35-40$.

Komnitsas, K. and Zaharaki, D., 2007. Geopolymerisation: A review and prospects for mineral industry. Mineral Engineering, v. 20, pp. 1261-1277.

Lü, L. and Lai, M.O. 1998. Mechanical Alloying (First Edn.), Springer publication, $25 \mathrm{p}$.

McCormick, A. V., Bell, A. T. and Radke, C. J., 1989, Multinuclear NMR investigation of the formation of aluminosilicate anions. Journal of Physical Chemistry, v. 93, no. 5, pp. 1741-1744.

Nugteren, H. W., Butselaar-Orthlieb, V. C. L. and Izquierdo, M., 2009, High strength geopolymers produced from coal combustion fly ash. Global NEST Journal, v. 11, no. 2, pp. 155-161.

Provis, J. L. and van Deventer, J. S. J., 2007a. Geopolymerisation kinetics. 1. In situ energy-dispersive X-ray diffractometry, Chemical Engineering Science, v. 62, pp. 2309-2317.

Provis, J. L. and van Deventer, J. S. J., 2007b, Direct measurement of the kinetics of geopolymerisation by in-situ energy dispersive X-ray diffractometry. Journal of Materials Science, v. 42 , pp. 2974-2981.

Singh, P. S., Bastow, T. and Trigg, M., 2005, Structural studies of geopolymers by ${ }^{29} \mathrm{Si}$ and ${ }^{27} \mathrm{Al}$ MAS-NMR. Journal of Materials Science, v. 40, pp. 3951-3961.

Temuujin, J., Minjigmaab, A., Rickarda, W., Leea, M., Williamsa, I. and Arie van, R., 2009, Preparation of metakolin base geopolymer coating on metal substrates as thermal barrier. Applied Clay Science, v. 46, no. 3, pp. 265-270.

United Nations, 1997, Glossary of Environment Statistics, Studies in Methods, New York, Series F, no. 67.

Wang, H., Li, H. and Yan, F., 2005, Synthesis and mechanical properties of metakaolinite-based geopolymer. Colloids and Surfaces A: Physicochemical and Engineering Aspects, v. 268, pp. 1-6.

Yip, C. K., Lukey, G. C. and van Deventer, J. S. J., 2005, The coexistence of geopolymeric gel and calcium silicate hydrate at the early stage of alkaline activation. Cement and Concrete Research, v. 35, no. 9, pp. 1688-1697. 